Research Article

\title{
Analysis of the Creeping Phenomenon of Linear Feed System Based on the Rigid-Flexible Coupling Model
}

\author{
Ruijun Liang $\mathbb{D}^{D}$, Wenlong Hao, Wenfeng Ran, and Wenhua Ye \\ School of Mechanical and Electrical College, Nanjing University of Aeronautics and Astronautics, Nanjing 210016, China \\ Correspondence should be addressed to Ruijun Liang; lruijun@nuaa.edu.cn
}

Received 3 April 2021; Accepted 25 June 2021; Published 5 July 2021

Academic Editor: Junhong Park

Copyright ( 2021 Ruijun Liang et al. This is an open access article distributed under the Creative Commons Attribution License, which permits unrestricted use, distribution, and reproduction in any medium, provided the original work is properly cited.

\begin{abstract}
A mathematical model of the creeping phenomenon based on the mechanical model of the linear feed system was established. The dynamic characteristic parameters of each fixed joint were obtained by Yoshimura's integral. Using the method, only the dynamic characteristic parameters of the joint surface per unit area with simple structure need to be studied, and then, the dynamic characteristic parameters of the whole joint surface can be obtained by integration. Based on the principle of the half-power bandwidth method and the frequency response function identification, the dynamic parameters of each moving joint were solved by the method of experimental modal analysis. Through the parameters of the fixed and moving joints, a rigid body model of the feed system and a flexible body model including the power transmission parts (ball screw pair) and the motion guide parts (guide slide pair and rolling bearing) were, respectively, established. And then, a rigid-flexible coupling dynamic model of the feed system was obtained through the constraint relationships between joints. The influence of both the external load and the feed rate on the fluctuation of motion speed of the system was analyzed from this model. The difference between the experimental results and the simulation results on a feed system platform is not greater than $10 \%$, which verifies the creeping phenomenon. This conclusion can provide a basis for the optimization of the dynamic performance of the ball screw linear-feeding workbench.
\end{abstract}

\section{Introduction}

As a moving part of general equipment, a linear worktable's accuracy has an important influence on the working accuracy of the equipment. The factors that affect the accuracy of motion of the feeding worktable mainly include static errors [1] such as geometric errors, thermal errors of the mechanical parts, and dynamic errors [2] such as deformation and vibration during operation of the worktable, respectively. Among them, the research on the static error has been relatively complete [3-7], while the impact of the dynamic error factors on the accuracy of equipment becomes an issue.

When a feeding worktable runs in a state of low speed with a heavy load, the phenomenon of periodic working and halting, both fast and slow, is called the creeping phenomenon, also called the stick-slip motion, which is a type of dynamic error. The time interval between the occurrences of the creeping phenomenon is uncertain [8], which causes an uneven movement of the worktable and seriously affects the working accuracy and the performance of the equipment $[9,10]$. At the same time, it also causes wear of the moving parts in the feed system and reduces the service life of the equipment.

Creeping on a machine tool feeding system is a form of self-excited vibration, which is generally improved and suppressed by improving the dynamic characteristics of the feed system. It is pointed out that, in $[11,12]$, the factors affecting the creeping phenomenon mainly include (1) the friction condition of the feed system, (2) the operating speed of the feed system, (3) the stiffness condition of the feed system, and (4) the magnitude of the load, respectively. The relationship between the critical stick-slip speed of the workbench and the structural parameters of the workbench was derived by using the nonlinear least square method in an earlier study [13]. The relationship between the critical stickslip speed and the axial stiffness of the ball screws was obtained in an earlier study [14]. 
With the continuous application of virtual simulation technology in the study of the creeping phenomenon, different types of friction models [15-18] have been established and verified by the simulation. A two-degree-of-freedom mathematical model [19] was used in an earlier study to simulate the stick-slip motion of the guide moving and agreed with the experimental results. A dynamic model of the creeping phenomenon of the feed system based on the LuGre model [20] was established, and the state of motion of the creeping was obtained through simulation analysis. A dynamic model was established based on Newton's law and Kirchhoff's law, and based on the model results, the airgap and external interference were controlled [21, 22]. A study carried out the dynamic simulation of the creeping process [23], and the influence of various factors on the creeping phenomenon was analyzed in it.

This paper studies mechanism of the creeping phenomenon and the factors that affect creeping phenomenon, and based on the mechanical model of the linear feed system, a mathematical model of its creeping phenomenon is established. On this basis, the rigid and flexible dynamic coupling model of the feed system was established, and the effects of the moving speed and load on its creeping dynamic performance are simulated and analyzed. The simulation results are verified on our designed feed system performance test platform [24].

\section{Mathematical Model of Creeping of the Feed System}

A feed system usually performs linear reciprocating motion through the motion conversion. Its rigid body model is shown in Figure 1, in which the rolling-bearing pair, the screw-nut pair, and the guide-slider pair are flexible joints having relative motion, and the others are fixed joints with fixed connections.

The feed system can be simplified as the mechanical model shown in Figure 2, the driving part $A$ drives the driven part $B$ to move at a constant speed $v$, the displacement of $B$ is $x$, the friction force of the moving pair is $F$, and the dynamic characteristics are of an equivalent spring having stiffness $K$ and a damper with damping $C$, respectively.

The motion equation of the mechanical model is

$$
K\left(x_{0}+v t-x\right)-C(\dot{x}-v)-F=M \ddot{x},
$$

where $M$ is the mass of the driven part, $x_{0}$ is the compression amount of the spring when the driven part starts to move, and $t$ is the time of movement in the driving part.

When the creeping phenomenon occurs, the motion of the driven part becomes unstable and self-excited oscillation takes place. During this time, the extent of expansion and contraction $\left(x_{0}+v t-x\right)$ of the spring changes with time, and the elastic force and the frictional force become unbalanced. Assume the deviation of $x$ relative to the displacement of the steady-state movement is as $\Delta_{x}$, and at the beginning of the movement, the friction force decreases with the increase of the speed, so $C_{1}<0$; then, (1) is

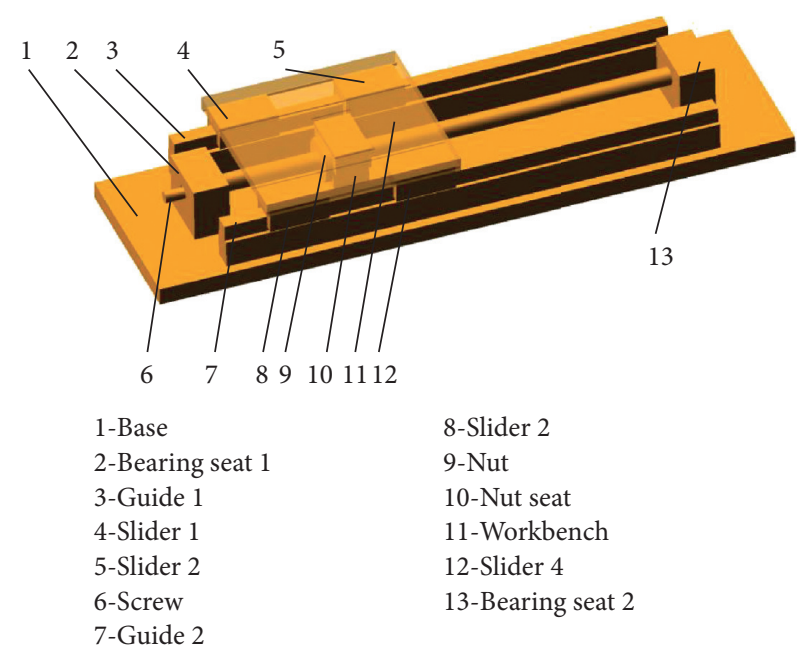

Figure 1: Rigid body model of a feed system.

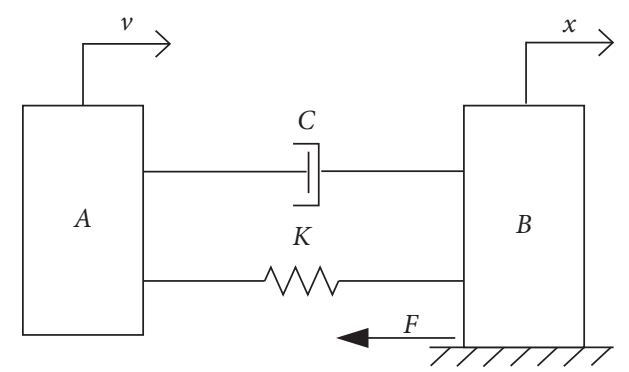

Figure 2: Simplified mechanical model of the feed system.

$$
M \ddot{\Delta}_{x}+\left(C+C_{1}\right) \dot{\Delta}_{x}+K \Delta_{x}=0 .
$$

Solve equation (2) to obtain

$$
\Delta_{x}=e^{-\varsigma \omega_{n} t_{1}}\left(A \sin \omega_{d} t_{1}+B \cos \omega_{d} t_{1}\right),
$$

where $\varsigma$ is the damping coefficient of the system, $\varsigma=C+C_{1} / 2 \sqrt{K M}, \omega_{n}$ is the natural frequency of the system and $\omega_{d}$ is the natural frequency of the system along with damping, $\omega_{d} \approx \omega_{n}=\sqrt{K / M}, t_{1}$ is the movement time of the driven part, and the constants $A$ and $B$ are determined according to the initial conditions, and they are

$$
\begin{aligned}
& A=\frac{v}{\omega_{n}}(-D \varsigma-1), \\
& B=\frac{v}{\omega_{n}}(2 \varsigma-D),
\end{aligned}
$$

and in equations, (4) and (5)

$$
D=\frac{\left(F_{s}-F_{d}\right)}{(v \cdot \sqrt{K M})},
$$

where $F_{s}$ is the force during the period from the beginning of the movement of the driving part till the start of the movement of the driven part, which is a static friction force, and $F_{d}$ is the dynamic friction force converted from $F_{s}$ when the driven part starts to move. Taking the derivative of 
equation (3) and ignoring the high-order term $\varsigma^{2}(\ll 1)$, speed of the self-excited vibration is obtained as

$$
\dot{\Delta}_{x}=v e^{-\varsigma \omega_{n} t_{1}}\left[(D-\varsigma) \sin \omega_{n} t_{1}-\cos \omega_{n} t_{1}\right] .
$$

As seen from equation (7), if

$$
e^{-\varsigma \omega_{n} t_{1}}\left[\left(D_{0}-\varsigma\right) \sin \omega_{n} t_{1}-\cos \omega_{n} t_{1}\right]<1,
$$

then the vibration speed of the driven part will gradually attenuate to zero. When,

$$
e^{-\zeta \omega_{n} t_{1}}\left[\left(D_{0}-\varsigma\right) \sin \omega_{n} t_{1}-\cos \omega_{n} t_{1}\right]=1,
$$

that is,

$$
D_{0} \approx \sqrt{4 \pi \varsigma}
$$
is

The critical speed at which the driven part does not creep

$$
v_{0}=\frac{F_{s}-F_{d}}{\sqrt{2 \pi\left(C+C_{1}\right) \sqrt{K M}}} .
$$

It can be seen from equation (11) that the factors affecting the creeping phenomenon include the dynamic characteristics of the feed system (stiffness $K$, damping $\left.\left(C+C_{1}\right)\right)$, the moving speed of the worktable $v$, and the load mass $M$. Among these, the dynamic characteristic is an essential factor that affects the creeping phenomenon.

\section{Joint Parameters}

3.1. Dynamic Parameters of the Fixed Joints. The fixed joints include the joints connected by bolts, which are base guide, base-bearing seat, workbench slider, workbench-nut seat, and nut-nut seat, and the joints with an interference fit, which are bearing seat-outer ring and inner ring-screw shaft. Based on the characteristic dynamic parameters of unit area of the fixed joints and then according to their area, the dynamic parameters of each fixed joint were obtained by Yoshimura's integral, as shown in Tables 1 and 2.

\subsection{Dynamic Parameters of the Motion Joints}

3.2.1. Theoretical Calculation. Dynamic parameters of the screw-nut pair, which was an example of the motion joint, were calculated based on Hertz contact theory. A single ball in the screw-nut pair contacts with the screw raceway at point $S$ and contacts with the nut raceway at point $N$. The axial preload force is $F_{a}$, the contact pressure angle is $\beta$, and the contact normal force is $P$, as shown in Figure 3 .

Force balance on the nut in an axial direction is

$$
F_{a}-P z \sin \beta \cos \lambda=0
$$

where $z$ is the number of balls, $\lambda$ is the helix angle of the screw and $\lambda=\arctan P_{h} / \pi d_{0}$, where $P_{h}$ is the screw lead, and $d_{0}$ is the screw diameter.

According to Hertz theory, the contact deformations $\delta_{S}$ and $\delta_{N}$ of a ball on the two raceways are

$$
\left\{\begin{array}{l}
\delta_{S}=\frac{2}{\pi n_{S}}\left\{\frac{1}{8}\left[\frac{3}{2}\left(\frac{1-\mu_{1}^{2}}{E_{1}}+\frac{1-\mu_{2}^{2}}{E_{2}}\right)\right]^{2}\right\}^{(1 / 3)}\left(\sum \rho_{S}\right)^{(1 / 3)} P^{(2 / 3)}, \\
\delta_{N}=\frac{2}{\pi n_{N}}\left\{\frac{1}{8}\left[\frac{3}{2}\left(\frac{1-\mu_{2}^{2}}{E_{2}}+\frac{1-\mu_{3}^{2}}{E_{3}}\right)\right]^{2}\right\}^{(1 / 3)}\left(\sum \rho_{S}\right)^{(1 / 3)} P^{(2 / 3)},
\end{array}\right.
$$

where $n_{S}$ and $n_{N}$ are the coefficient of the short axis of the ellipse formed by the contact deformation at the contact point $S$ and $N, \mu_{1}, \mu_{2}$, and $\mu_{3}$ are Poisson's ratio of the screw, ball, and nut, $E_{1}, E_{2}$, and $E_{3}$ are their elastic modulus, and the curvature $\sum \rho_{S}$ at $S$ and the curvature $\sum \rho_{N}$ at $N$ are

$$
\left\{\begin{array}{l}
\sum \rho_{S}=\frac{4}{d_{b}}-\frac{2}{r d_{b}}+\frac{2 \cos \beta \cos \lambda}{d_{0}-d_{b} \cos \beta}, \\
\sum \rho_{N}=\frac{4}{d_{b}}-\frac{2}{r d_{b}}+\frac{2 \cos \beta \cos \lambda}{d_{0}-d_{b} \cos \beta}
\end{array}\right.
$$

where $d_{b}$ is the ball diameter and $r$ is the curvature ratio of the ball to the raceway. In Figure 3, the contact deformation on the screw nut in an axial direction is

$$
\delta_{a}=\frac{\left(\delta_{S}+\delta_{N}\right)}{\sin \beta \cos \lambda},
$$

and the contact deformation on the screw nut in the radial direction is

$$
\delta_{r}=\frac{\left(\delta_{S}+\delta_{N}\right)}{\cos \beta \sin \lambda} .
$$

By combining equations (12)-(16), the axial and radial stiffness of the screw-nut joint can be obtained. The results are shown in Table 3. Regarding the screw-nut pair as a single-degree-of-freedom vibration system, we can get its natural frequency in axial $f_{a}$ and in radial $f_{r}$ from its axial and radial stiffness, respectively.

3.2.2. Experimental Modal Analysis. Dynamic parameters of the ball screw pair, the guide-slider pair, and the rollingbearing pair in the different directions were also identified with the help of the hammering test. The test scheme is 
TABle 1: Dynamic parameters of the bolted fixed joints.

\begin{tabular}{lcccc}
\hline Joints & $\begin{array}{c}\text { Normal stiffness, } \\
K_{n}\left(\times\left(10^{10} \mathrm{~N} / \mathrm{m}\right)\right)\end{array}$ & $\begin{array}{c}\text { Normal damping, } \\
C_{n}\left(\times\left(10^{8} \mathrm{~N} \cdot \mathrm{s} / \mathrm{m}\right)\right)\end{array}$ & $\begin{array}{c}\text { Tangential stiffness, } \\
K_{\tau}\left(\times\left(10^{10} \mathrm{~N} / \mathrm{m}\right)\right)\end{array}$ & $\begin{array}{c}\text { Tangential damping, } \\
C_{\tau}\left(\times\left(10^{8} \mathrm{~N} \cdot \mathrm{s} / \mathrm{m}\right)\right)\end{array}$ \\
\hline $\begin{array}{l}\text { Base guide } \\
\begin{array}{l}\text { Base-bearing } \\
\text { seat }\end{array}\end{array}$ & 43.47 & $7.551 \times 10^{-3}$ & $7.599 \times 10^{-3}$ & $29.30 \times 10^{-3}$ \\
$\begin{array}{l}\text { Workbench } \\
\text { slider }\end{array}$ & 12.15 & $2.111 \times 10^{-3}$ & $2.124 \times 10^{-3}$ & $8.190 \times 10^{-3}$ \\
$\begin{array}{l}\text { Workbench-nut } \\
\text { seat }\end{array}$ & 10.85 & $1.891 \times 10^{-3}$ & $1.903 \times 10^{-3}$ & $7.338 \times 10^{-3}$ \\
Nut-nut seat & 11.07 & $1.923 \times 10^{-3}$ & $1.935 \times 10^{-3}$ & $7.462 \times 10^{-3}$ \\
\hline
\end{tabular}

TABLe 2: Dynamic parameters of the interference fit joints.

\begin{tabular}{lcccc}
\hline Joints & $\begin{array}{c}\text { Axial stiffness, } \\
K_{a}\left(\times\left(10^{10} \mathrm{~N} / \mathrm{m}\right)\right)\end{array}$ & $\begin{array}{c}\text { Axial damping, } \\
C_{a}\left(\times\left(10^{8} \mathrm{~N} \cdot \mathrm{s} / \mathrm{m}\right)\right)\end{array}$ & $\begin{array}{c}\text { Radial stiffness, } \\
K_{r}\left(\times\left(10^{10} \mathrm{~N} / \mathrm{m}\right)\right)\end{array}$ & $\begin{array}{c}\text { Radial damping, } \\
C_{r}\left(\times\left(10^{8} \mathrm{~N} \cdot \mathrm{s} / \mathrm{m}\right)\right)\end{array}$ \\
\hline $\begin{array}{l}\text { Bearing seat- } \\
\text { outer ring }\end{array}$ & 0.643 & $1.61 \times 10^{-3}$ & $4.11 \times 10^{-3}$ & $0.411 \times 10^{-3}$ \\
$\begin{array}{l}\text { Inner ring-screw } \\
\text { shaft }\end{array}$ & 0.22 & $0.55 \times 10^{-3}$ & $2.75 \times 10^{-3}$ & $0.275 \times 10^{-3}$ \\
\hline
\end{tabular}
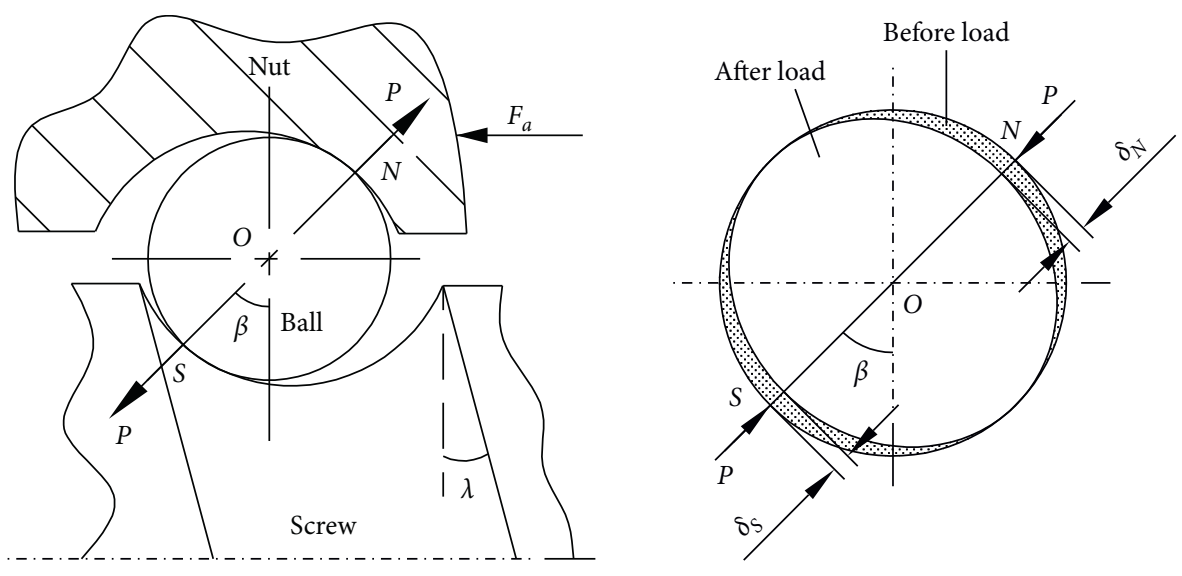

Figure 3: Force in the joint of screw nut.

TABLE 3: Calculation results for the screw-nut pair.

\begin{tabular}{lcccc}
\hline & $z$ & $d_{b}(\mathrm{~mm})$ & $d_{0}(\mathrm{~mm})$ & $\beta$ \\
\hline \multirow{4}{*}{ Basic parameters } & 47 & 3.175 & 25 & $45^{\circ}$ \\
& $P_{h}(\mathrm{~mm})$ & $r$ & $f_{a}(\mathrm{~N})$ & $M(\mathrm{~kg})$ \\
& 5 & 1.04 & 579 & 0.335 \\
\hline \multirow{2}{*}{ Calculation results } & $K_{a}\left(\mathrm{~N} \cdot \mathrm{m}^{-1}\right)$ & $f_{a} / \mathrm{Hz}$ & $K_{r}\left(\mathrm{~N} \cdot \mathrm{m}^{-1}\right)$ & $f_{r}(\mathrm{~Hz})$ \\
& $48.6 \times 10^{6}$ & 1917 & $1.83 \times 10^{5}$ & 117.63 \\
\hline
\end{tabular}

shown in Figure 4, and the test photos are shown in Figure 5. In the test, the excitation points were fixed, and the vibration pick-up points were moved.

The test points for the mode of the ball screw pair are shown in Figure 6. To test the axial parameters, the excitation points 1-4 were set on the end face of the nut, and any point was selected as the vibration pick-up point. To test the radial parameters, excitation points $1-12$ were set on the circumference of the nut, and point 1 was selected as the vibration pick-up point to avoid nodes. The measured frequency response is shown in Figure 7 . We obtained the stiffness and damping of the ball screw pair from the halfpower bandwidth method in Figure 7, as shown in Table 4.

Comparing the dynamic stiffness in Tables 5 and 6, it can be seen that the difference is not as big as $10 \%$. It indicates that the calculated and the experimental results can be mutually verified. The test points for the guide-slider pair is shown in Figure 8(a). To test the vertical parameters, the excitation points 1-6 were set on the plane of the slider, and point 1 was selected as the vibration pick-up point to avoid nodes. To test the lateral parameters, the excitation points 9-12 were set on the side plane of the slider, and point 7 was selected as the vibration pick-up point. The test points for the bearing are shown in Figures 8(b) and 8(c). To test the axial parameters, eight excitation points were set on each end of the bearing seat, and point 1 was selected as the vibration pick-up point to avoid the middle nodes; to test the radial 


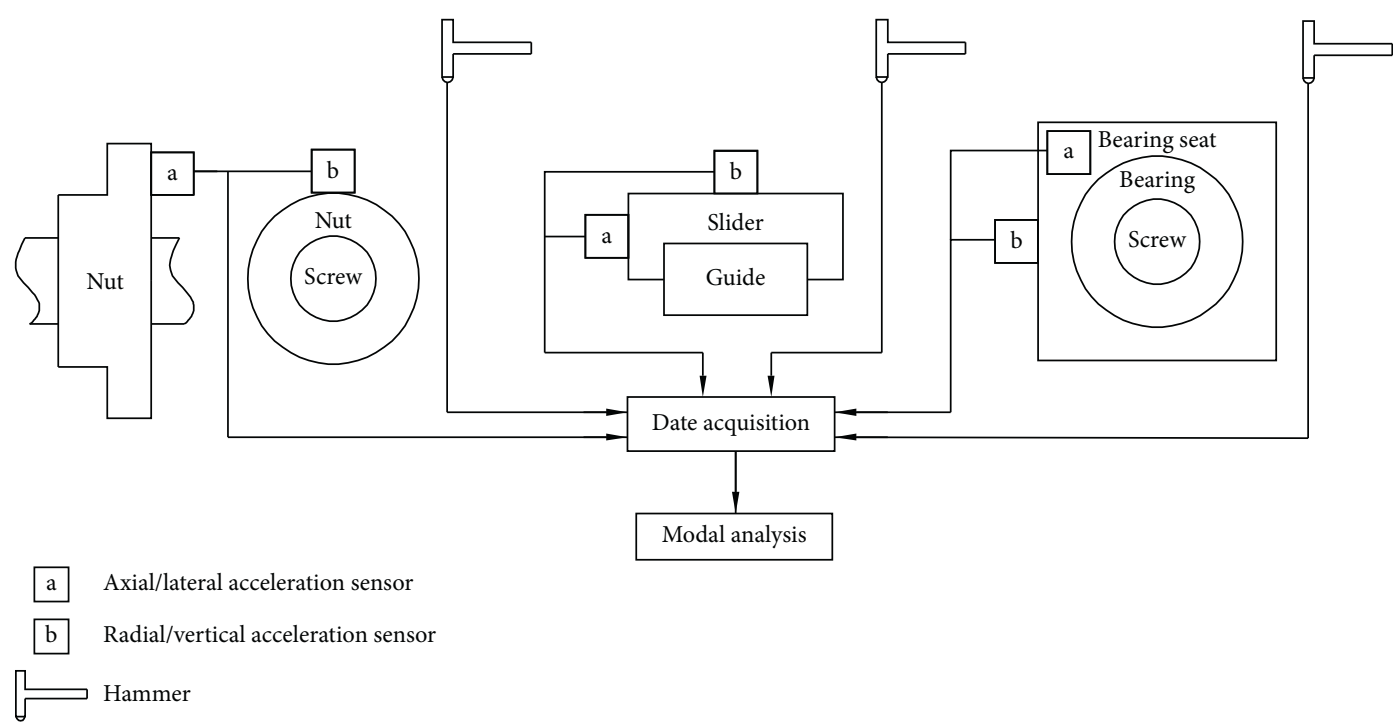

Figure 4: Experimental modal test scheme for the motion joints.

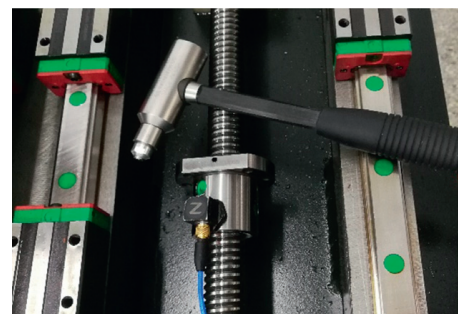

(a)

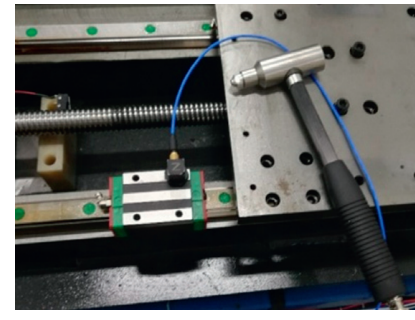

(b)

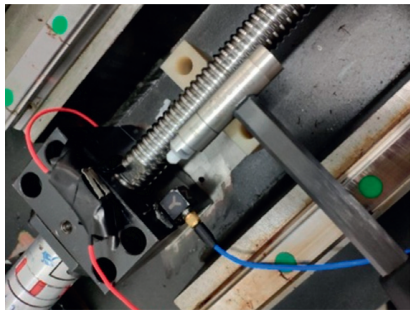

(c)

FIgURE 5: Test photos. (a) For screw-nut pair. (b) For guide-slider pair. (c) For bearing pair.

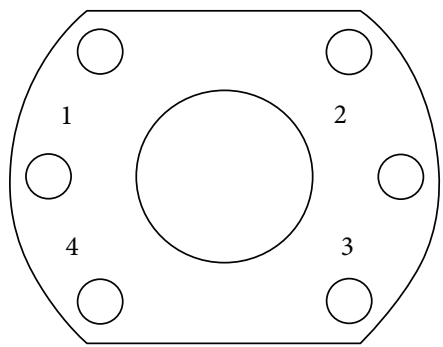

(a)

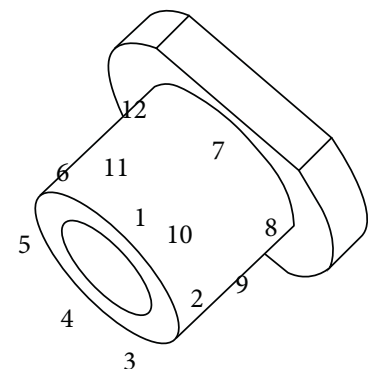

(b)

Figure 6: Test points for screw-nut pair. (a) Test points on the end face. (b) Test points on the circumference.

parameters, six excitation points were set on each side of the bearing seat, and point 1 was selected as the vibration pickup point.

Stiffness and damping of the bearing pair and of the guide-slider pair were then obtained, as shown in Tables 5 and 6 , respectively.

\section{Creeping Simulation of the Feed System}

4.1. Rigid-Flexible Coupling Dynamic Model. The process of establishing the dynamic model of the feed system based on rigid-flexible coupling is shown in Figure 9. First, the threedimensional solid model of all components was established. 


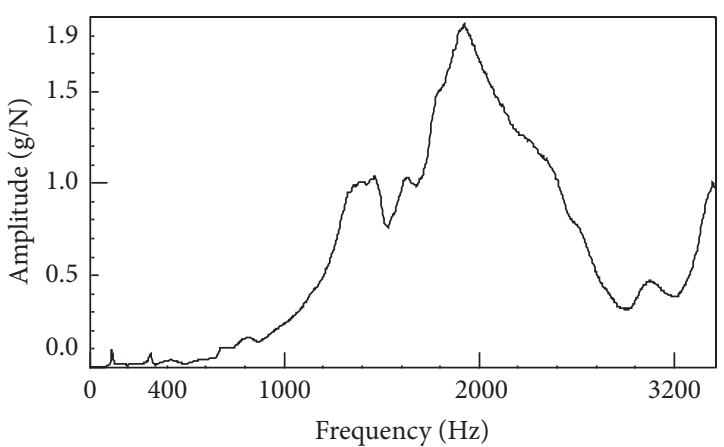

(a)

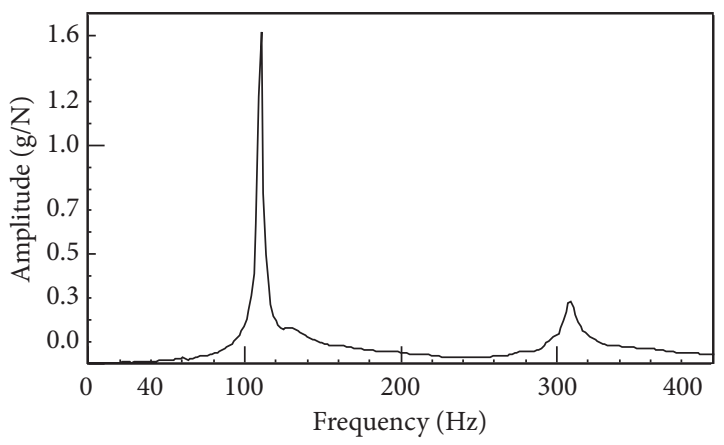

(c)

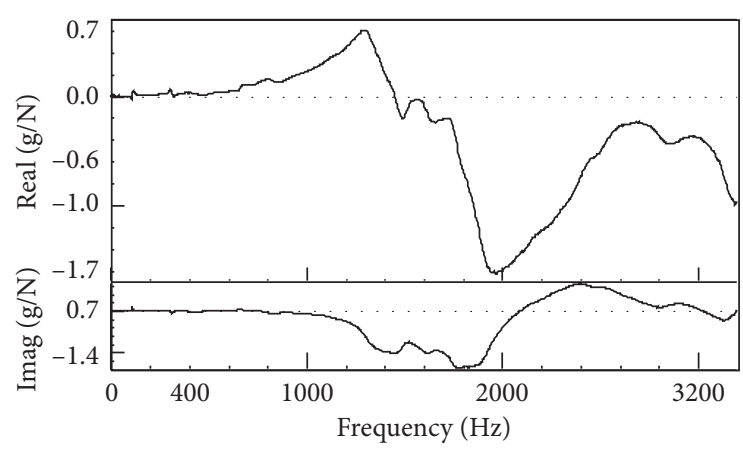

(b)

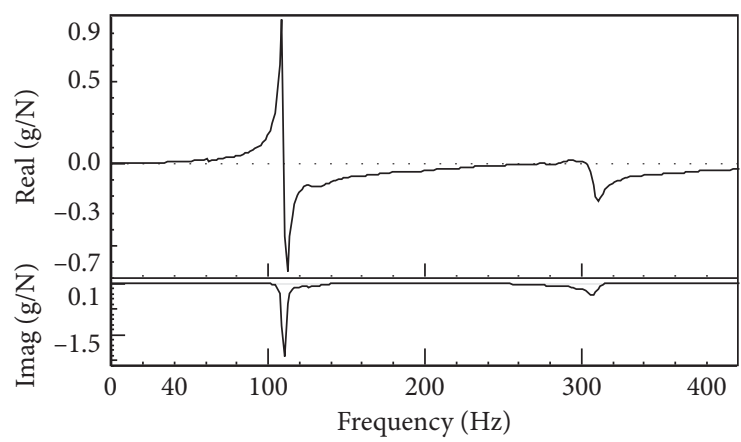

(d)

Figure 7: Frequency response of the screw-nut pair. (a) Axial amplitude frequency. (b) Axial real and imaginary frequency. (c) Radial amplitude frequency. (d) Radial real and imaginary frequency.

TABLE 4: Stiffness and damping of the screw-nut pair.

\begin{tabular}{lccc}
\hline Axial stiffness, $K_{a}(\mathrm{~N} / \mathrm{m})$ & Axial damping, $C_{a}(\mathrm{~N} \cdot \mathrm{s} / \mathrm{m})$ & Radial stiffness, $K_{r}(\mathrm{~N} / \mathrm{m})$ & Radial damping, $C_{r}(\mathrm{~N} \cdot \mathrm{s} / \mathrm{m})$ \\
\hline $51.6 \times 10^{6}$ & 898.88 & $1.62 \times 10^{5}$ & 1.68 \\
\hline
\end{tabular}

TABLE 5: Dynamic parameters of the guide-slider pair.

\begin{tabular}{lccc}
\hline Vertical stiffness, $K_{Z}(\mathrm{~N} / \mathrm{m})$ & Vertical damping, $C_{Z}(\mathrm{~N} \cdot \mathrm{s} / \mathrm{m})$ & Lateral stiffness, $K_{Y}(\mathrm{~N} / \mathrm{m})$ & Lateral damping, $C_{Y}(\mathrm{~N} \cdot \mathrm{s} / \mathrm{m})$ \\
\hline $52.3 \times 10^{6}$ & 258.28 & $55.2 \times 10^{6}$ & 297.17 \\
\hline
\end{tabular}

TABLE 6: Dynamic parameters of bearing pair.

\begin{tabular}{lccc}
\hline Axial stiffness, $K_{a}(\mathrm{~N} / \mathrm{m})$ & Axial damping, $C_{a}(\mathrm{~N} \cdot \mathrm{s} / \mathrm{m})$ & Radial stiffness, $K_{r}(\mathrm{~N} / \mathrm{m})$ & Radial damping, $C_{r}(\mathrm{~N} \cdot \mathrm{s} / \mathrm{m})$ \\
\hline $9.38 \times 10^{6}$ & 60.61 & $5.02 \times 10^{6}$ & 68.14 \\
\hline
\end{tabular}

Then, the models of the screw-nut pair, the guide-slider pair, and the rolling-bearing pair were imported into finite element software to generate the modal neutral files (MNFs) for the flexible body. Then, the other components' solid model and the MNFs were imported into dynamic analysis of mechanical systems. Finally, the fixed and motion joints were defined based on the joint parameters to establish the dynamic model of the rigid-flexible coupling feed system.

The joints were defined by the constraints created among the components, as shown in Figure 10. The fixed joints were defined by creating the contact forces according to the dynamic parameters (see Tables 1 and 2). The motion joints of both moving pairs and rotating pairs were defined by creating the sleeve forces based on the dynamic parameters (see Tables 4-6), and the friction coefficients were added to define the moving pairs and rotating pairs. The torque and speed were also specified on the lead screw.

4.2. Influence of Working Load and Feed Speed on Creeping. According to the feed system creeping model in Section 1, when the dynamic parameters and the friction coefficient 


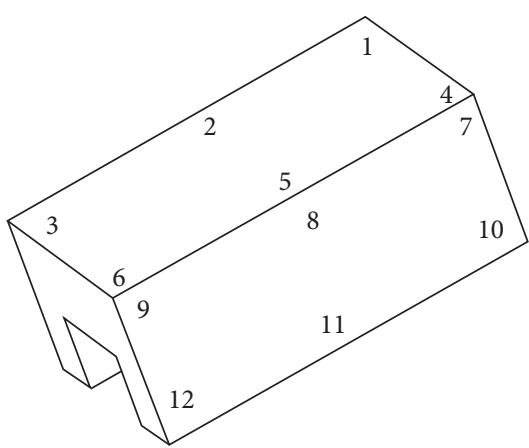

(a)

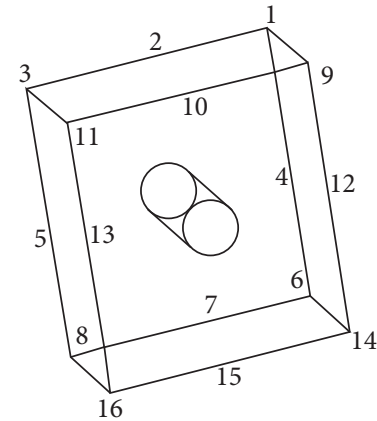

(b)

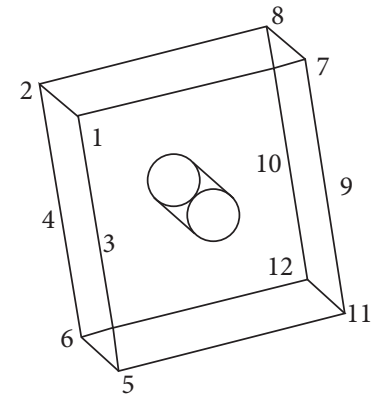

(c)

Figure 8: Test points. (a) For guide-slider pair. (b) For bearing axial. (c) For bearing radial.

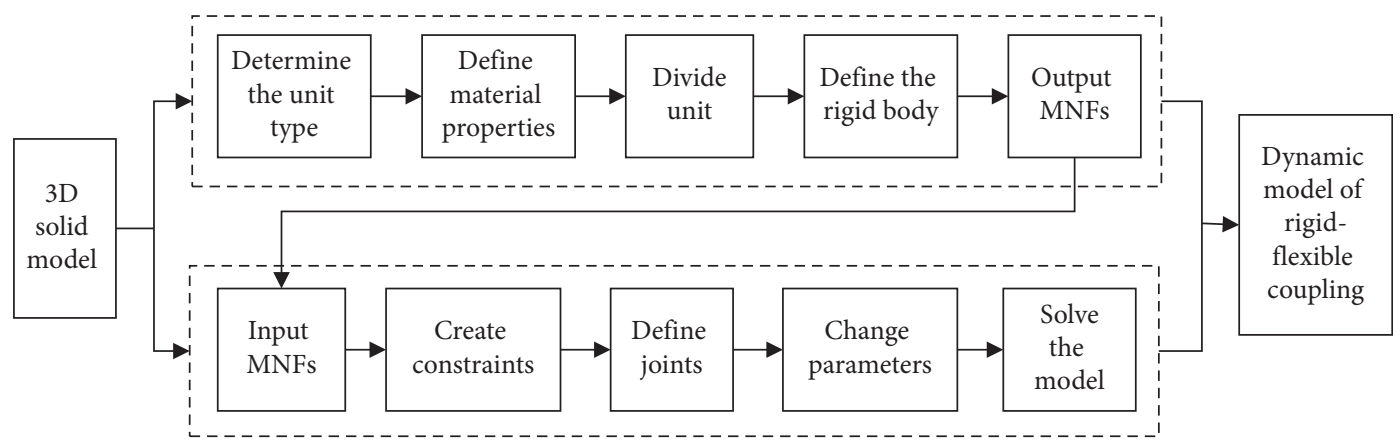

Figure 9: Flowchart for establishing the dynamic model.

have been determined, the factors that affect the feed system creeping phenomenon are the cutting load and feed speed.

The feed speed of the workbench was set to $1 \mathrm{~mm} / \mathrm{s}$, and the load was to the moving part of the workbench as per the actual working conditions, as shown in Table 7 (the force applying part is the Earth). The fluctuations in the speed of the moving part under different loads are obtained through the simulation, as shown in Figure 11. It can be seen that when the feed speed is $1 \mathrm{~mm} / \mathrm{s}$, corresponding to the three loads, the maximum fluctuations of the speed of the moving part are $0.0316 \mathrm{~mm} / \mathrm{s}$, $0.033 \mathrm{~mm} / \mathrm{s}$, and $0.0351 \mathrm{~mm} / \mathrm{s}$, respectively, and the maximum fluctuation rates are $3.16 \%, 3.3 \%$, and $3.51 \%$, respectively. This shows that, as the load increases, the amount of fluctuation in the feed rate increases. It is also seen that when the load increases, the critical speed of the feed system without creeping oscillation will decrease, which is consistent with the result of equation (11).

The working load was given as No. 3 in Table 7, and the feed speeds of the workbench were set to $0.5 \mathrm{~mm} / \mathrm{s}, 1 \mathrm{~mm} / \mathrm{s}$, and $2 \mathrm{~mm} / \mathrm{s}$, respectively. The fluctuations in the speed of the workbench at different feed speeds are obtained through the simulation, as shown in Figure 12. It can be seen that corresponding to the three feed speeds, the maximum fluctuations in the speed are $0.0203 \mathrm{~mm} / \mathrm{s}, 0.0351 \mathrm{~mm} / \mathrm{s}$, and $0.0577 \mathrm{~mm} / \mathrm{s}$, and the maximum fluctuation rates are $4.06 \%$, $3.51 \%$, and $2.89 \%$, respectively. This shows that, as the feed speed increases, the fluctuation of the feed speed decreases; when the feed system moves at a low speed, the smaller the movement speed, the more serious the creeping phenomenon becomes.

\section{Experimental Verification}

We apply a test platform for the feed system, as shown in Figure 13 to verify the established simulation model. The platform consists of the feeding unit and the follow-up unit. The follow-up unit moves synchronously with the feeding unit so that the feeding unit receives the load during its movement.

The experiments used the working condition of simulation, i.e., the feed rate was set at $1 \mathrm{~mm} / \mathrm{s}$, and the three sets of loads in Table 7 were applied. During the linear motion of the feed unit, the data from the motor encoder and the grating were collected, and the speed fluctuation was obtained, as shown in Figure 14. The maximum fluctuations of the workbench's feed speed are $0.028 \mathrm{~mm} / \mathrm{s}, 0.030 \mathrm{~mm} / \mathrm{s}$, and $0.031 \mathrm{~mm} / \mathrm{s}$ to these three sets of loads, i. e., the maximum fluctuation rates are $2.8 \%, 3.0 \%$, and $3.1 \%$, respectively.

The workbench was applied the No. 3 load in Table 7, the feed speed was set to $0.5 \mathrm{~mm} / \mathrm{s}, 1 \mathrm{~mm} / \mathrm{s}$, and $2 \mathrm{~mm} / \mathrm{s}$, respectively. The speed fluctuation of the feed movement of the workbench was measured and is shown in Figure 15. The maximum fluctuations of the workbench's feed speed are $0.019 \mathrm{~mm} / \mathrm{s}, 0.031 \mathrm{~mm} / \mathrm{s}$, and $0.054 \mathrm{~mm} / \mathrm{s}$ to these three feed speeds, i.e., the maximum fluctuation rates are $3.8 \%, 3.1 \%$, and $2.7 \%$, respectively.

We listed the measured and simulated feed speed fluctuations under the different loads and feed speeds in Tables 8 and 9. It can be seen that the difference between the measurement result and the simulation result is about $10 \%$, which verifies the rigid-flexible coupling model of the feed system. 


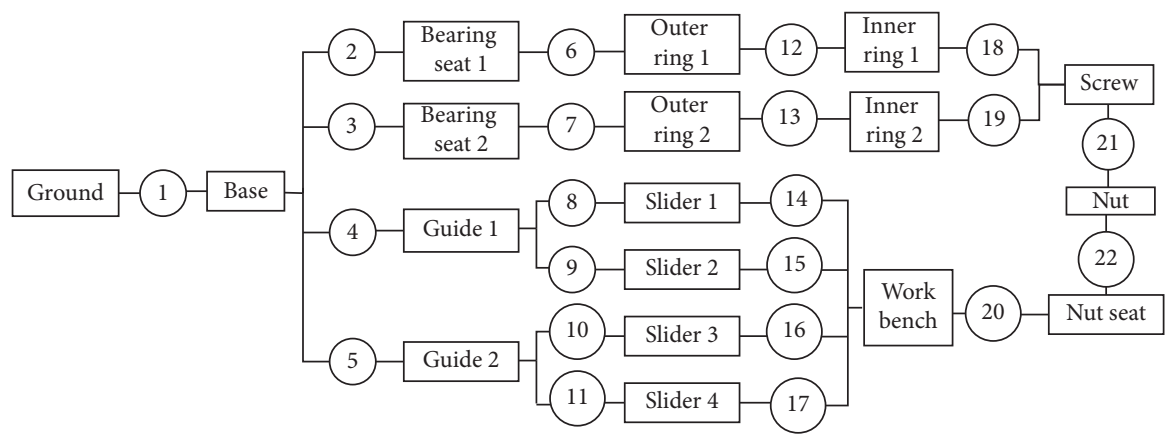

$1,2,3,4,5,6,7,14,15,16,17,18,19,20,22$--Fixed pair;

$8,9,10,11$--Moving pair;

12, 13, 21 --Rotating pair

Figure 10: Definition of the joint in the rigid-flexible model.

TABLE 7: Load setting.

\begin{tabular}{lccc}
\hline No. & $X$-axis $(\mathrm{N})$ & $Y$-axis $(\mathrm{N})$ & $Z$-axis $(\mathrm{N})$ \\
\hline 1 & 174 & 151 & 524 \\
2 & 252 & 228 & 787 \\
3 & 434 & 407 & 1001 \\
\hline
\end{tabular}

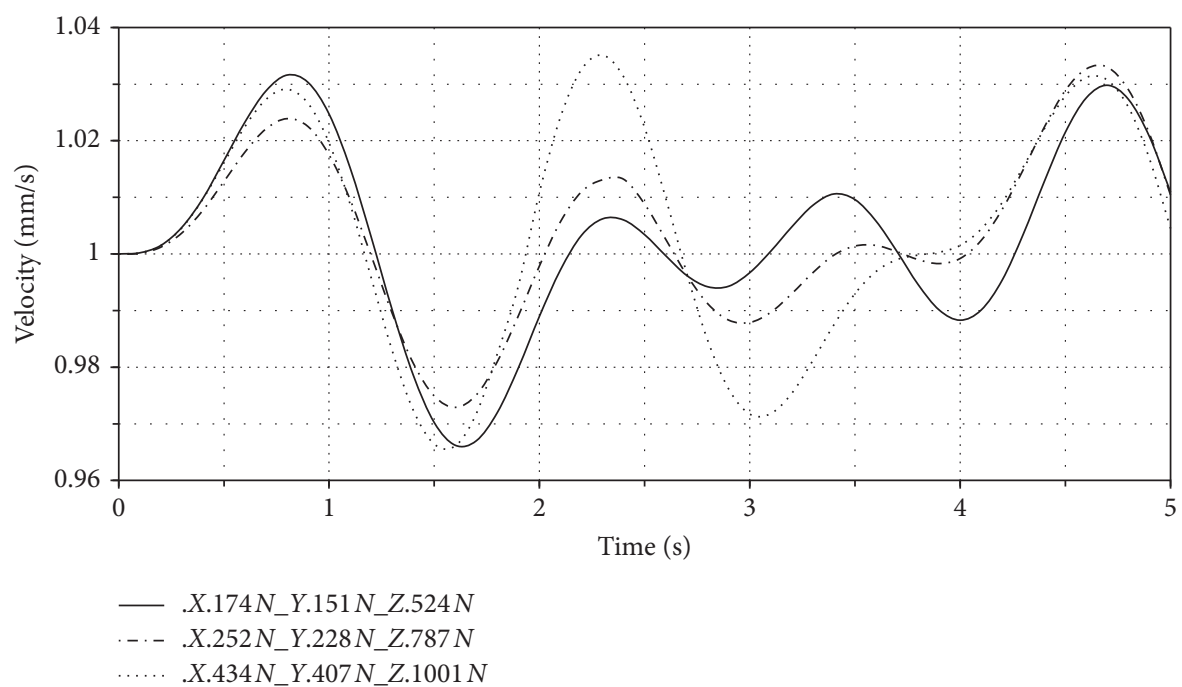

FIgURE 11: Simulated speed under different loads. 


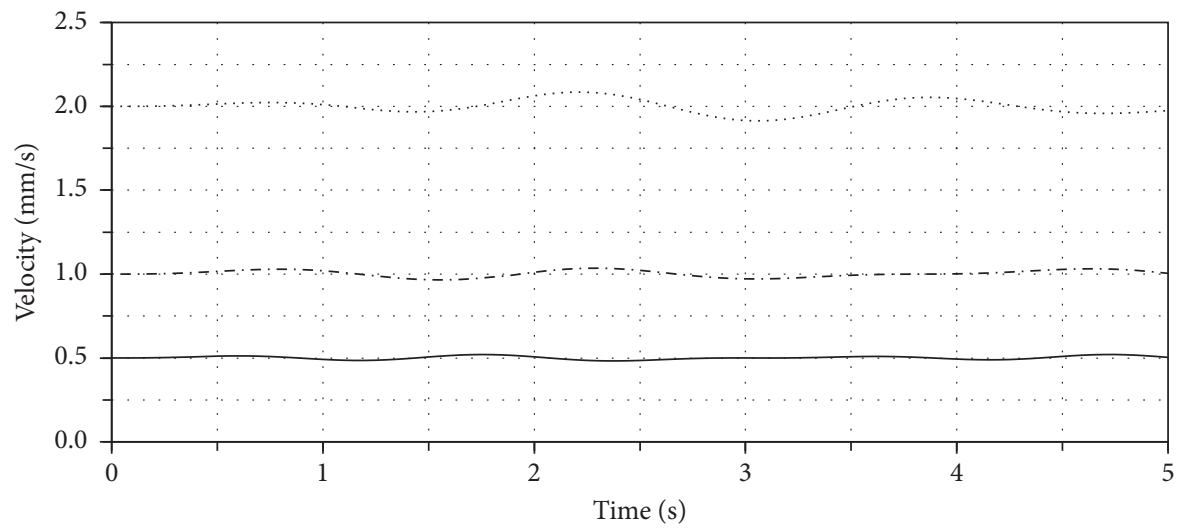

— Workbench_velocity_0.5 $\mathrm{mm} / \mathrm{s}$

-. - Workbench_velocity_1 $\mathrm{mm} / \mathrm{s}$

Workbench_velocity_2 $\mathrm{mm} / \mathrm{s}$

Figure 12: Simulated speed under different feed speeds.

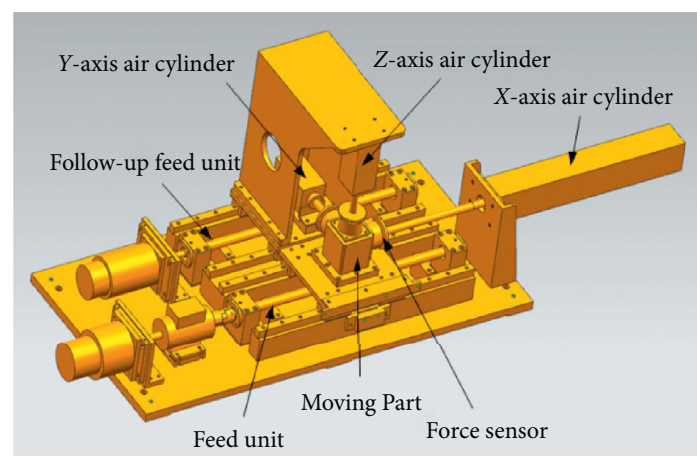

(a)

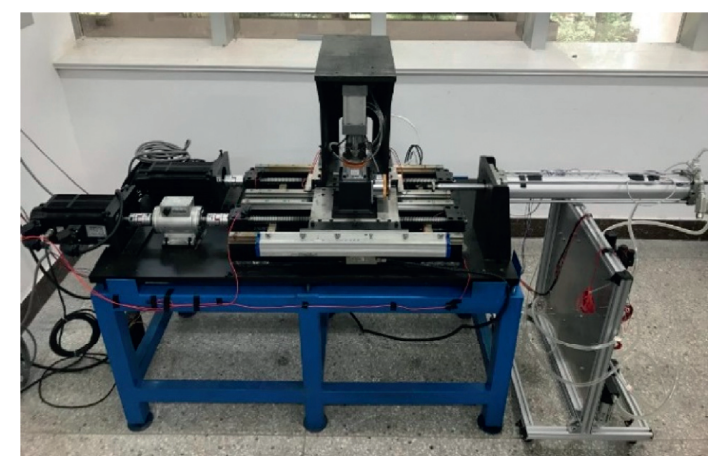

(b)

Figure 13: Test platform for the feed system. (a) Model. (b) Photo.

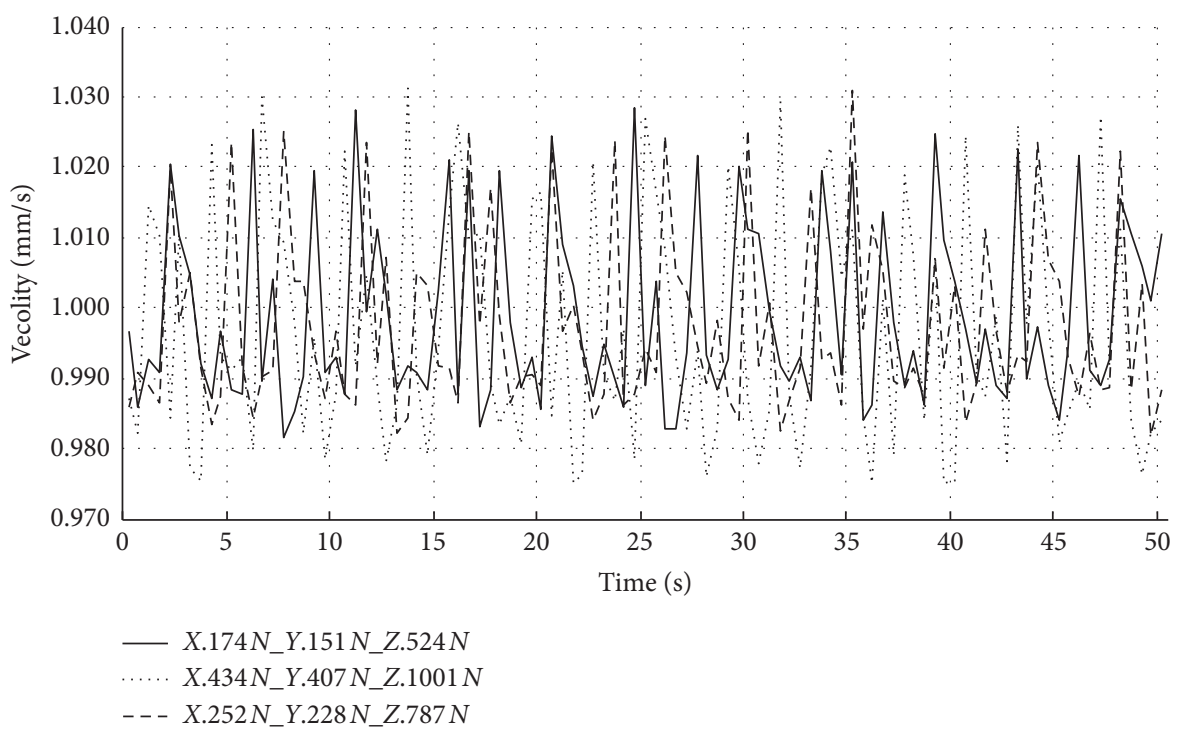

Figure 14: Measured speeds under different loads. 


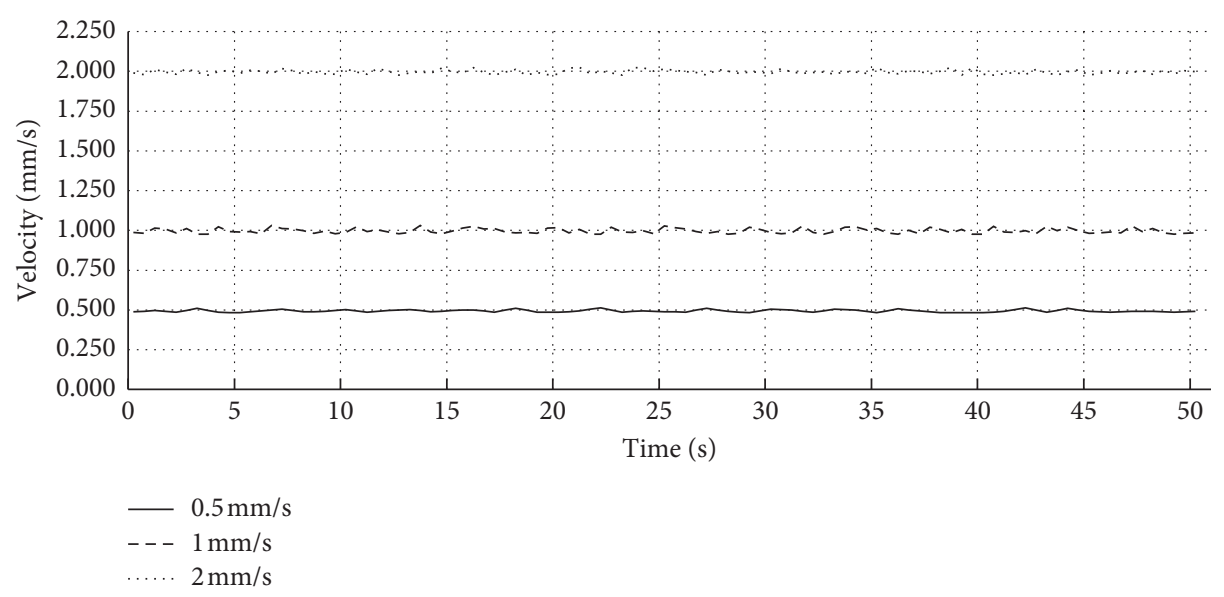

FiguRE 15: Measured speeds at different feed speeds.

TABLE 8: Maximum fluctuations of feed speed under different loads.

\begin{tabular}{lccc}
\hline Load $(\mathrm{N})$ & Experiment $(\mathrm{mm} / \mathrm{s})$ & Simulation $(\mathrm{mm} / \mathrm{s})$ & Error $(\%)$ \\
\hline$X .174-Y .151-Z .524$ & 0.028 & 0.0316 & 11.4 \\
$X .252-Y .228-Z .787$ & 0.030 & 0.033 & 9.1 \\
$X .434-Y .407-Z .1001$ & 0.031 & 0.0351 & 11.7
\end{tabular}

TABle 9: Maximum fluctuations of the feed rate at different feed rates.

\begin{tabular}{lccc}
\hline Feed speed $(\mathrm{mm} / \mathrm{s})$ & Experiment $(\mathrm{mm} / \mathrm{s})$ & Simulation $(\mathrm{mm} / \mathrm{s})$ & \\
\hline 0.5 & 0.019 & 0.0203 & 6.4 \\
1 & 0.031 & 0.0351 & 11.7 \\
2 & 0.054 & 0.0577 & 6.4 \\
\hline
\end{tabular}

\section{Conclusions}

(1) The factors affecting the creeping phenomenon include the dynamic parameters of the feed system, the moving speed of the workbench, and the load on the moving parts. The dynamic character is an essential factor affecting the creeping phenomenon. The dynamic parameters are solved through the combination of Yoshimura's integral and experimental modal analysis method, which can reduce the difficulty and workload of the test and also provides a new way of thinking for the solution of the dynamic parameters of the feed system.

(2) As the load on the moving parts increases, the fluctuation of the feed speed increases, and the critical speed decreases when the creeping phenomenon does not occur.

(3) As the feed speed of the moving parts increases, the fluctuation of the feed speed decreases. When the feed system moves at a low speed, the smaller the speed of movement is, the more obvious the creeping phenomenon becomes.

(4) The difference between the experimental and simulation results is less than $10 \%$, and it is verified that the established rigid-flexible coupling dynamic model of the feed system can accurately simulate the creeping phenomenon of the feed system.

\section{Data Availability}

The data used to support the findings of this study are included within the article.

\section{Conflicts of Interest}

The authors declare that there are no conflicts of interest regarding the publication of this paper.

\section{Acknowledgments}

This work was supported by the Jiangsu Provincial Key Research and Development Program (Grant no. BE2020779) and National Natural Science Foundation of China (Grant no. 51575272). The authors express their deep gratitude for the invaluable support of the institution.

\section{References}

[1] H. Pahk and S. W. Lee, "Thermal error measurement and real time compensation system for the CNC machine tools incorporating the spindle thermal error and the feed axis thermal error," International Journal of Advanced Manufacturing Technology, vol. 20, no. 7, pp. 487-494, 2002.

[2] H. Yang, Z. Wang, T. Zhang, and F. Du, "A review on vibration analysis and control of machine tool feed drive systems," International Journal of Advanced Manufacturing Technology, vol. 107, pp. 503-525, 2020. 
[3] G. S. Wei, L. H. Seok, M. Rahman et al., "A fine tool servo system for global position error compensation for a miniature ultra-precision lathe," International Journal of Machine Tools and Manufacture, vol. 47, pp. 1302-1310, 2007.

[4] G. W. Cui, Y. Lu, D. Gao et al., "A novel error compensation implementing strategy and realizing on Siemens 840D CNC systems," International Journal of Advanced Manufacturing Technology, vol. 61, pp. 595-608, 2012.

[5] J. Li, F. G. Xie, X. J. Liu et al., "Geometric error identification and compensation of linear axes based on a novel 13-line method," International Journal of Advanced Manufacturing Technology, vol. 87, pp. 2269-2283, 2016.

[6] H. Y. Shen, J. Z. Fu, Y. He et al., "On-line asynchronous compensation methods for static/quasi-static error implemented on CNC machine tools," International Journal of Machine Tools and Manufacture, vol. 60, pp. 14-26, 2012.

[7] E. Wagner, "A new method of diminishing errors of form generated by the imprecision of CNC machines," Procedia Technology, vol. 22, pp. 13-19, 2016.

[8] C. Rosario, R. M. Shmuel, B. Itay et al., "Stabilizing stick-slip friction," Physical Review Letters, vol. 107, Article ID 024301, 2011.

[9] P. L. Yang, W. L. Zheng, S. Z. Hao, and K. Chen, "Stick-slip mechanism study of CNC heavy-duty horizontal lathe feed systems based on dynamics," in Proceedings of the 2011 International Conference on Quality, Reliability, Risk, Maintenance, and Safety Engineering, pp. 518-522, Xi'an, China, June 2011.

[10] X. S. Mei, M. Tsutsumi, T. Tao et al., "Study on the compensation of error by stick-slip for high-precision table," International Journal of Machine Tools and Manufacture, vol. 44, pp. 503-510, 2004.

[11] M. Yin, W. T. Cheng, L. J. Bai et al., "Numerical control machine tool motion simulation and analysis of parts of the crawling phenomenon," Advanced Materials Research, vol. 971-973, pp. 592-595, 2014.

[12] C. L. Yu, R. J. Liang, W. Li et al., "Analysis of creeping mechanism and eliminating measures of creeping phenomenon of machine feeding system," IOP Conference Series: Materials Science and Engineering, vol. 688, Article ID 033030, 2019.

[13] L. L. Liu and Z. Y. Wu, "Comprehensive parameter identification of feed servo systems with friction based on responses of the worktable," Mechanical Systems and Signal Processing, vol. 64-65, pp. 257-265, 2015.

[14] L. L. Liu, Z. Y. Wu, and H. Z. Liu, "Modeling and analysis of the crossfeed servo system of a heavy-duty lathe with friction," Mechanics Based Design of Structures and Machines, vol. 41, pp. 1-20, 2013.

[15] X. Li, Z. Y. Yao, and R. C. Wu, "Modeling and analysis of stick-slip motion in a linear piezoelectric ultrasonic motor considering ultrasonic oscillation effect," International Journal of Mechanical Sciences, vol. 107, pp. 215-224, 2016.

[16] S. Ozaki and K. Hashiguchi, "Numerical analysis of stick-slip instability by a rate-dependent elastoplastic formulation for friction," Tribology International, vol. 43, pp. 2120-2133, 2010.

[17] H. Y. Cha, J. Choi, H. S. Ryu et al., "Stick-slip algorithm in a tangential contact force model for multi-body system dynamics," Journal of Mechanical Science and Technology, vol. 25, pp. 1687-1694, 2011.

[18] D. Wang and C. Xu, "A tangential stick-slip friction model for rough interface," Journal of Mechanical Engineering, vol. 50, pp. 129-134, 2014, in Chinese.
[19] O. Bilkay and O. Anlagan, "Computer simulation of stick-slip motion in machine tool slideways," Tribology International, vol. 37, pp. 347-351, 2004.

[20] B. W. Zhong, L. N. Sun, L. G. Chen, and Z. Wnag, "The dynamics study of the stick-slip driving system based on LuGre dynamic friction model," in Proceedings of the 2011 IEEE International Conference on Mechatronics and Automation, pp. 584-589, Beijing, China, August 2011.

[21] Y. Sun, J. Xu, H. Wu, G. Lin, and S. Mumtaz, "Deep learning based semi-supervised control for vertical security of maglev vehicle with guaranteed bounded airgap," IEEE Transactions on Intelligent Transportation Systems, pp. 1-12, 2021.

[22] Y. Sun, J. Xu, G. Lin, G. Wen, and L. Wang, "RBF neural network-based supervisor control for maglev vehicles on an elastic track with network time-delay," IEEE Transactions on Industrial Informatics, p. 1, 2020.

[23] S. Y. Bi and G. C. Du, "The dynamic simulation of the crawling problems of machine tools based on ADAMS," Journal of Applied Sciences, vol. 13, no. 18, pp. 3762-3765, 2013.

[24] M. K. Huang, R. J. Liang, W. Y. Shao et al., "Design of measurement and control system for performance test installment of tool linear feed system," Mechanical Science and Technology for Aerospace Engineering, vol. 38, pp. 1048-1054, 2019. 